\title{
Experimental study of R450A drop-in performance in an r134a small capacity refrigeration unit
}

Article in International Journal of Refrigeration · August 2017

DOI: $10.1016 / j . j$ jrefrig.2017.08.010

CITATIONS

0

3 authors, including:

\section{Pavel Makhnatch}

KTH Royal Institute of Technology

12 PUBLICATIONS 9 CITATIONS

SEE PROFILE
READS

26

Some of the authors of this publication are also working on these related projects:

Project

FPU12/02841 View project

Application of new refrigerants with low Global Warming Potential in commercial refrigeration and air

Project conditioning systems View project

All content following this page was uploaded by Adrián Mota-Babiloni on 07 September 2017. 


\section{Accepted Manuscript}

Title: Experimental study of R450A drop-in performance in an r134a small capacity refrigeration unit

Author: Pavel Makhnatch, Adrián Mota-Babiloni, Rahmatollah Khodabandeh

PII: $\quad$ S0140-7007(17)30329-8

DOI: $\quad$ http://dx.doi.org/doi: 10.1016/j.ijrefrig.2017.08.010

Reference: JIJR 3728

To appear in: International Journal of Refrigeration

Received date: 13-1-2017

Revised date: $\quad 22-8-2017$

Accepted date: $\quad 23-8-2017$

Please cite this article as: Pavel Makhnatch, Adrián Mota-Babiloni, Rahmatollah Khodabandeh, Experimental study of R450A drop-in performance in an r134a small capacity refrigeration unit, International Journal of Refrigeration (2017), http://dx.doi.org/doi:

10.1016/j.ijrefrig.2017.08.010.

This is a PDF file of an unedited manuscript that has been accepted for publication. As a service to our customers we are providing this early version of the manuscript. The manuscript will undergo copyediting, typesetting, and review of the resulting proof before it is published in its final form. Please note that during the production process errors may be discovered which could affect the content, and all legal disclaimers that apply to the journal pertain. 


\title{
Experimental study of R450A drop-in performance in an R134a small capacity refrigeration unit
}

\author{
Pavel Makhnatch $^{\text {a,* }}$, Adrián Mota-Babiloni ${ }^{\text {a,b }}$, Rahmatollah Khodabandeh ${ }^{\text {a }}$
}

${ }^{a}$ Royal Institute of Technology, Department of Energy Technology, Division of Applied

Thermodynamics and Refrigeration, Brinellvägen 68, 10044 Stockholm, Sweden

${ }^{\mathrm{b}}$ ISTENER Research Group, Department of Mechanical Engineering and Construction, Campus de Riu Sec s/n, University Jaume I, E-12071 Castellón de la Plana, Spain

\section{HIGHLIGHTS}

- R450A is tested in an R134a small capacity refrigeration unit.

- Evaporating temperature is varied between $-15^{\circ} \mathrm{C}$ and $12.5^{\circ} \mathrm{C}$.

- Average mass flow rate and cooling capacity are $9.1 \%$ and $9.9 \%$ lower for R450A.

- Average compressor power consumption and COP values are 7.2 and $2.9 \%$ lower for R450A.

- R450A can be considered as R134a drop-in replacement if decrease in cooling capacity is acceptable.

\begin{abstract}
The Kigali's amendment to the Montreal Protocol has highlighted the hydrofluorocarbons (HFCs) phase out as a priority to reduce the future global Earth's mean temperature increase. $\mathrm{R} 134 \mathrm{a}$ is the most abundant HFC in the atmosphere and therefore it must be substituted using environmentally benign alternatives. In the short term, blends of HFCs and hydrofluoroolefins can replace R134a. This paper experimentally evaluates R450A (GWP of 547), a nonflammable mixture of R1234ze(E) and R134a, in an R134a small capacity refrigeration system. The controlled experimental conditions cover evaporating temperatures from -15 to $12.5^{\circ} \mathrm{C}$ and condensing temperature of 25,30 and $35{ }^{\circ} \mathrm{C}$ (36 tests in total for each refrigerant). The experimental results showed that with only a thermostatic expansion valve adjustment the average R450A cooling capacity and COP are 9.9 and 2.9\% lower than those measured using R134a. Besides, the observed compressor discharge temperature values of R450A are not greater than that of R134a.
\end{abstract}

\footnotetext{
${ }^{*}$ Corresponding Author:

Tel: +4687906885

E-mail address: pavelma@kth.se
} 
Keywords: vapor compression system; GWP; drop-in replacement; zeotropic refrigerant; HFC/HFO mixture, energy assessment

\section{Nomenclature}

$c_{p} \quad$ specific heat at constant pressure $\left(\mathrm{kJ} \mathrm{kg}^{-1} \mathrm{~K}^{-1}\right)$

$c_{v} \quad$ specific heat at constant volume $\left(\mathrm{kJ} \mathrm{kg}^{-1} \mathrm{~K}^{-1}\right)$

COP coefficient of performance

$D \quad$ pipe inner diameter $(\mathrm{m})$

$h \quad$ enthalpy $\left(\mathrm{kJ} \mathrm{kg}^{-1}\right)$

$\dot{m}_{\text {ref }}$ refrigerant mass flow rate $\left(\mathrm{g} \mathrm{s}^{-1}\right)$

$P_{\text {comp }}$ motor-compressor electrical power consumption (W)

$\dot{Q}_{\text {evap }}$ cooling capacity (W)

$S C D \quad$ subcooling degree $(\mathrm{K})$

SHD superheating degree $(\mathrm{K})$

$T \quad$ temperature $\left({ }^{\circ} \mathrm{C}\right)$

$v \quad$ refrigerant velocity $\left(\mathrm{m} \mathrm{s}^{-1}\right)$

wt. weight percent

Greek

$\rho \quad$ density $\left(\mathrm{kg} \mathrm{m}^{-3}\right)$

Subscripts

amb ambient

in inlet

c condenser

evap evaporator 
$\begin{array}{ll}\text { disc discharge } & \\ \text { out outlet }\end{array}$

Abbreviations

AHRI Air Conditioning, Heating, and Refrigeration Institute

ANSI American National Standards Institute

ASHRAE American Society of Heating, Refrigerating and Air-Conditioning Engineers

GWP global warming potential for time horizon of 100 years

HFC hydrofluorocarbon

HFO hydrofluoroolefin

IHX internal heat exchanger

TXV thermostatic expansion valve

\section{Introduction}

The climate observations show a continuous increase in the global mean temperature of the Earth during the past years (GISTEMP Team, 2016). In response to the threat of climate change, many countries have agreed to hold the increase in the global average temperature this century to well below $2{ }^{\circ} \mathrm{C}$ above pre-industrial levels and pursue efforts to limit the temperature increase to $1.5{ }^{\circ} \mathrm{C}$ above pre-industrial levels (United Nations, 2015). Up to $0.5{ }^{\circ} \mathrm{C}$ of global temperature rise is believed to be avoided by global reduction of the hydrofluorocarbons (HFCs), as it is agreed internationally within the mechanisms of Montreal Protocol (European Commission, 2017).

As a refrigerant, R134a was introduced to replace R12 in mobile air conditioning systems, and medium evaporation temperature stationary refrigeration and chillers, and gradually become the most abundant HFC in the atmosphere (World Meteorological Organization, 2014). Moreover, its annual mean concentration in the atmosphere is steadily growing (at 7.6\% rate in 2012 as compared to 2011). The existing concentration of R134a in the atmosphere creates radiative forcing of $0.01 \mathrm{~W} \mathrm{~m}^{-2}$, which is nearly a half of the approximated radiative forcing of all HFCs in the atmosphere combined. R134a is therefore identified as a dominant contributor to global warming among all the HFCs (Myhre et al., 2013). 
There are several lower GWP alternatives to R134a in vapor compression systems with very different characteristics. In domestic refrigerators, pure hydrocarbons as R600a, R290 or their mixtures (Lee et al., 2008 and Rasti et al., 2013) can reduce the global warming contribution due to the better energy efficiency. Besides, the use of another low GWP natural refrigerant as carbon dioxide (R744) can be detrimental regarding energy efficiency (Aprea et al., 2012). Refrigerants R152a and R32 have also been considered during the recent years, both showing higher than R134a energy efficiency (Bolaji, 2010).

Several hydrofluoroolefins (HFOs) have been considered as replacements to R134a in medium evaporation temperature refrigeration systems (McLinden et al., 2014). The most relevant proposed HFOs are R1234yf and R1234ze(E) (Molés et al., 2014) and present a global warming potential (GWP) values lower than unity at 100 years' time horizon (Myhre et al., 2013). Although these first HFOs have been recently developed, their characteristics as refrigerant fluids are well defined (low flammability, lower cooling capacity and performance in retrofit substitution and currently high cost). R1234yf has been mostly limited to retrofitted MACs (Qi, 2015; Ortega Sotomayor and Reis Parise, 2016) and R1234ze(E) to new design air-cooled and water-cooled chillers (Mota-Babiloni et al., 2016).

To accelerate the HFCs phase out and to introduce working fluids with reduced GWP values in existing refrigeration and air conditioning systems, several HFC/HFO mixtures are being tested, registered and commercialized (Raabe, 2016). Since mildly flammable alternatives to R134a have been proposed in the form of the pure HFOs, the main interest is therefore in HFC/HFO mixtures that can be classified as A1 non-flammable, non-toxic fluids under the ASHRAE designation category. R450A (Mota-Babiloni et al., 2015a) and R513A (Kontomaris et al., 2013 and Mota-Babiloni et al., 2017) are examples of such mixtures that are developed to substitute $\mathrm{R} 134 \mathrm{a}$ in systems where the use of pure HFOs (R1234yf or R1234ze(E)) cannot be accepted.

R450A is a non-flammable mixture of R134a and R1234ze(E) with GWP of 547 and no ozone depletion potential. Since it has been recently commercialized, there are still very few studies and data about this HFC/HFO mixture in the open literature. In a previous study, Mota-Babiloni et al. (2015a) have published an experimental comparison between R450A and R134a (at ten operating conditions for each refrigerant) in a medium refrigeration capacity test bench. R450A was presented as a good candidate to replace R134a with a TXV adjustment because of very similar measured COP $( \pm 1 \%$ deviation $)$ and $6 \%$ lower average cooling capacity. Using the internal heat exchanger (IHX) the observed R450A COP increases between 0.5 and $7 \%$ (IHX effectiveness between 17 and 30\%) (Mota-Babiloni et al., 2015b). Using the R450A experimental results obtained by Mota-Babiloni et al. (2016a) (2016b), the performance of a shell and micro-fin tube evaporator (Mendoza-Miranda et al., 2016a) and an open-type reciprocating compressor (Mendoza-Miranda et al., 2016b) have been modeled.

Besides, Schultz and Kujak (2013) presented experimental results for R450A (formerly known as developing refrigerant mixture $\mathrm{N}-13 \mathrm{~b})$ tested in a 230 refrigerating tons $(808.9 \mathrm{~kW})$ nominal 
capacity water-cooled screw chiller installation. The comparison was performed at $6.7{ }^{\circ} \mathrm{C}$ temperature of chilled water leaving the evaporator and $29.5^{\circ} \mathrm{C}$ temperature of cooling water entering the condenser. The results indicate the decrease of cooling capacity (15\%) and COP (2\%) compared to R134a.

Due to the lack of experimental points available in the literature (only 9, and shown as a relative deviation), the aim of this paper is to present the experimental drop-in energy performance of $\mathrm{R} 450 \mathrm{~A}$ in a small refrigeration system equipped with a hermetic compressor and plate heat exchangers over a wide range of points. The evaporating temperature was varied between -15 and $12.5^{\circ} \mathrm{C}$ (at steps of $2.5^{\circ} \mathrm{C}$ ) and condensing temperature tested was 25,30 and $35^{\circ} \mathrm{C}$, being a total of 36 tests for each refrigerant.

\section{Main characteristics of $\mathbf{R 4 5 0 A}$ as $R 134 a$ alternative}

$\mathrm{R} 450 \mathrm{~A}$ is a blend of $\mathrm{R} 134 \mathrm{a}$ with $\mathrm{R} 1234 \mathrm{ze}(\mathrm{E})$ at a composition of $42 / 58$ mass percentage. Similarly to R134a, this blend is classified as a non-flammable and non-toxic refrigerant and therefore can be considered in the equipment originally designed for R134a. Moreover, R450A has no ozone depleting potential and GWP of 547, which is approximately $42 \%$ of the R134a value. The main characteristics of R450A and R134a are displayed in Table 1.

The normal boiling point of R450A is slightly higher than that of R134a, so it can be considered for most applications where R134a is used, except where evaporating temperatures are below $23{ }^{\circ} \mathrm{C}$, at which the pressure in the evaporator can become lower than atmospheric pressure and thus the risk of system contamination will appear.

Unlike pure R134a, R450A is a zeotropic refrigerant mixture and therefore exhibits temperature glide $(0.61 \mathrm{~K}$ at $0.1 \mathrm{MPa}$ pressure and $0.63 \mathrm{~K}$ at $0.2 \mathrm{MPa})$ during evaporation/condensation.

Reduced vapor and liquid density of R450A will influence the refrigerant mass flow of the system at the conditions of similar volumetric flow of vapor/liquid respectively for both refrigerants. Additionally, lower vapor and liquid density indicate reduced pressure drop that is expected for R450A. In vapor fraction, the pressure drop is further increased due to the higher vapor viscosity of R450A, whereas in liquid fraction the increase can be slightly compensated by reduced liquid viscosity.

Isobaric heat capacities are very similar for both refrigerants; therefore, no significant effect of these properties is expected. However, specific heat ratio of R450A is slightly lower which lowers the ideal compression volumetric efficiency and affects the ideal work of isentropic compression (the latter is also affected by the relative molar mass that is greater for R450A). The liquid thermal conductivity of R450A is $6.3 \%$ lower, and the vapor thermal conductivity is $1.7 \%$ higher than reference values of R134a, and it consequently affects heat transfer rate in heat exchangers. 
Theoretical vapor compression cycle simulations have been performed for both refrigerants using the refrigerant property data obtained from REFPROP 9.1 (Lemmon et al., 2013). The results presented in Table 2 are calculated at conditions of $30 /-5{ }^{\circ} \mathrm{C}$ middle condensing/evaporating temperature, 0.7 isentropic compression efficiency, no volumetric compression losses and 10.5/7 K superheating/subcooling degree.

R450A can be expected to operate at reduced condensing and evaporating pressures. The calculated compressor discharge temperature is $3.5 \mathrm{~K}$ lower than that of R134a. It is predicted to have both lower refrigerating effect and lower vapor density at the compressor inlet, resulting in the reduced volumetric cooling capacity. The specific compression work is expected to be lower than that of R134a. Considering the lower refrigerant vapor density at the compressor inlet the R450A compression work is expected to be lower than for R134a under the modeled conditions. The COP is predicted to be slightly higher for R450A when compared to R134a at the modeled conditions of the simple vapor compression cycle.

\section{Experimental procedure}

The experimental tests are carried out in a test rig that simulates the operation of a small capacity vapor compression system. It is composed of the main circuit and two secondary circuits, the heat load closed loop, used to vary the evaporating temperatures between -15 and $12.5^{\circ} \mathrm{C}$; and the cooling load open loop used to vary the condensing temperatures between 25 and $35^{\circ} \mathrm{C}$.

\subsection{Experimental setup}

The experimental apparatus that was used to test both refrigerants R450A and R134a is a small capacity vapor compression refrigeration system, as presented in Figure 1. The main refrigeration circuit of the system consists of a fully hermetic rotary compressor with a motor rating of $550 \mathrm{~W}$ nominal power and displacement of $15.44 \mathrm{~cm}^{3}$ per revolution $(2840 \mathrm{rpm}$ at 220 V $50 \mathrm{~Hz}$ ) that is originally designed for R134a. The polyolester oil is used in the compressor, and its return to the compressor is ensured by the usage of an oil separator. Both evaporator and condenser are plate heat exchangers that are designed to work with R134a at medium temperature refrigeration conditions. The amount of refrigerant flow into the evaporator is controlled by the R134a thermostatic expansion valve (TXV). The heat load to the evaporator is supplied by a $43 \%$-wt. ethylene glycol based secondary refrigerant with a constant speed pump and a controlled heater. The condenser is cooled by an open loop of tap water controlled by a water regulating valve to maintain the condenser pressure at the expected level. 
The measuring sensors and instruments used are: $\mathrm{T}$ type thermocouples (calibrated to $\pm 0.11 \mathrm{~K}$ of uncertainty) used to measure the temperatures at the inlet and the outlet of each main component (main and secondary circuits); two calibrated pressure sensor transducers $( \pm 0.08 \%$ of uncertainty, full scale best straight line) used to measure the condensation and evaporation pressures; a differential pressure sensor $(0.25 \%$ of uncertainty, reading) used to measure the refrigerant pressure difference between evaporator inlet and outlet; a Coriolis type flow meter $( \pm 0.5 \%$ uncertainty, reading) used to measure the refrigerant mass flow; a two configurable multi transducers $( \pm 0.2 \%$ uncertainty, reading) used to measure the electric consumption of motor-compressor set and the heaters. It should be noted that the components and the pipes of the system are insulated using closed cell elastomeric nitrile rubber foam (thermal conductivity of $33 \mathrm{~mW} \mathrm{~m}{ }^{-1} \mathrm{~K}^{-1}$ at $0{ }^{\circ} \mathrm{C}$ ) to minimize losses to ambient and allow measuring more accurate results.

Finally, all the measurements are collected by a data acquisition system and transferred to a personal computer, in which the data is displayed and registered every 10 seconds. The main parameters of the system (temperature, pressure, refrigerant mass flow rate and compressor power consumption) are continuously monitored and recorded at steady-state conditions under a period of $30 \mathrm{~min}$. Thus, 180 direct measurements are recorded at each condition. The high and low pressures at the steady state conditions are within an interval of $\pm 2.5 \mathrm{kPa}$ and all the measured temperatures are within $\pm 0.5 \mathrm{~K}$. Then, once a steady state is recorded, the data used as a steady state test are obtained averaging over a period of $10 \mathrm{~min}$ (60 measurements). The rest of the steady-state output parameters are obtained using properties given by the REFPROP v9.1 database (Lemmon et al., 2013).

\subsection{Tests conditions}

The performed tests are intended to simulate the operating conditions of a typical medium evaporating temperature small capacity refrigeration system. A total of 72 points has been measured representing twelve evaporating temperatures at three condensing temperatures for each of the two analyzed refrigerants, Table 3. The maximum deviation for condensing temperature at different evaporating temperatures was $\pm 0.2 \mathrm{~K}$. The standard deviation of superheating degree was $0.6 \mathrm{~K}$, and the subcooling varied depending on the operating conditions and superheating degree adjustment. The higher R450A subcooling degree was necessary to avoid bubbles and hunting because TXV was not replaced for the new refrigerant, only the screw was adjusted (drop-in replacement). The laboratory ambient temperature was between 25.2 and $28.0^{\circ} \mathrm{C}$ for R134a, and between 21.6 and $26.6^{\circ} \mathrm{C}$ for R450A.

When the alternative refrigerant was introduced, a drop-in replacement was performed as defined by the Air Conditioning, Heating, and Refrigeration Institute (AHRI) Low GWP Alternative Refrigerants Evaluation Program, which allow only minor modifications (AHRI, 
2015). In this sense, the modifications that were performed are the refrigerant charge adjustment and the superheating degree regulation through the screw of the thermal expansion valve.

\section{Results and discussion}

This section presents and discusses the parameters used to perform the experimental analysis of the R450A performance in comparison to R134a. The main parameters studied are mass flow rate, compression pressure ratio, cooling capacity, $\mathrm{COP}$ and discharge temperature.

The uncertainties of the directly measured temperature, pressure, power and refrigerant mass flow values correspond to the individual uncertainties of the measurement equipment. The rest of the parameters is calculated from the measured values of the independent variables. The uncertainties of cooling capacity ( $\dot{Q}_{\text {evap }}$ ) and coefficient of performance (COP) are therefore evaluated following the methodology of Moffat (1988). The maximum uncertainties of the resulting $\dot{Q}_{\text {evap }}$ and COP values are $0.51 \%$ and $0.55 \%$, respectively. These values do not include the uncertainties of the enthalpy values obtained from the REFPROP v9.1 database.

The experimental results are presented at different average evaporating temperatures for each of the tested average condensing temperatures. Tables 4 and 5 contain the summary of the R134a and R450A tests.

\subsection{Mass flow rate}

The experimental refrigerant mass flow rate in vapor compression systems is a function of compressor's displacement volume, compression volumetric efficiency and vapor density at the compressor suction point. The experimental observations indicate on average the $9.1 \%$ reduction of mass flow in case of refrigerant R450A as compared to the reference R134a values, Figure 2. Given the constant compressor's displacement volume, and taking into account small volumetric losses of rotary compression, the reduction in mass flow rate is mainly due to the $7.9 \%$ lower, on average, refrigerant vapor density at the compressor inlet.

Table 6 lists the observed extreme values of velocities at the test bench lines, calculated using Equation (1). The suction line minimum and maximum velocities are equal for both refrigerants given the constant rotational speed of the compressor. However, the discharge line velocities of $\mathrm{R} 450 \mathrm{~A}$ are slightly lower for $\mathrm{R} 450 \mathrm{~A}$, due to the slight increase in compression pressure ratio for R450A ( $0.9 \%$ on average) in comparison to R134a, Figure 3 . The maximum liquid line velocities of R450A are lower than for R134a due to the lower liquid and vapor densities of R450A. Overall, no significant reduction of velocities has been observed. However, the slightly lower values for R450A lead to reduced pressure drops in the system and therefore positively influence the resulting system efficiency of R450A system. 


$$
\mathrm{v}_{\text {line }}=\frac{\dot{m}_{\text {ref }}}{\rho_{\text {line }} \pi \frac{D_{\text {line }}^{2}}{4}}
$$

\subsection{Cooling capacity}

The cooling capacity ( $\dot{Q}_{\text {evap }}$ ) is obtained using Equation (2) as the product of refrigerant mass flow and the enthalpy difference between the outlet and the inlet of the evaporator (also called refrigerating effect). The refrigerant mass flow is directly measured in the installation using the Coriolis mass flow meter, and enthalpy values are obtained using state property data from REFPROP v9.1 based on the pressure and temperature measurements at the outlet and the inlet of the evaporator.

$\dot{Q}_{\text {evap }}=\dot{m}_{\text {ref }}\left(h_{\text {out }}-h_{\text {in }}\right)_{\text {evap }}$

The cooling capacity measurement is validated by a power meter that registers the electrical power consumed by the heater. Figure 4 shows the evaporator heat balance of both refrigerants tested. Although the heater power is below that of measured on the refrigerant side, the deviation between both values always remains below 15\%. The deviation is greater at lower heat transfer values; this is due to the losses to the ambient that are greater at low evaporating temperatures.

The measured cooling capacity values are presented in Figure 5. The resulting cooling capacity of R450A is $9.9 \%$ on average lower than that of R134a system.

Although the theoretically predicted refrigeration effect of R450A is lower than that of R134a under equal conditions, the measured refrigeration effect of R450A on average matches that of R134a. Regardless of the superheating degree (higher superheating degree slightly reduces compression volumetric efficiency but also increases the refrigerating effect), the higher tested subcooling degree of R450A increases refrigerating effect and influences the cooling capacity. Given the similar refrigerating effect, the reduction of cooling capacity is primarily due to the observed refrigerant mass flow reduction.

The measured cooling capacity reduction is greater than that shown by Mota-Babiloni et al. (2015a). It might be due to higher R450A subcooling degree. Schultz and Kujak (2013) 
indicated even higher cooling capacity reduction, but the results of this study cannot be directly compared to the present paper due to the difference between the methodologies of both studies.

\subsection{COP (coefficient of performance)}

Then, the Coefficient of Performance (COP) represents the performance of the refrigeration system and is calculated using Equation (3).

$C O P=\dot{Q}_{\text {evap }} / P_{\text {comp }}$

In addition to the cooling capacity values, the COP calculation requires the compressor power consumption that is directly obtained from the power meter measurements.

Figure 6 shows the experimental values of compressor power consumption for both refrigerants at the tested conditions. The compressor power consumption is always lower when compressing $\mathrm{R} 450 \mathrm{~A}$ than $\mathrm{R} 134 \mathrm{a}$ and the average reduction in compressor power is $7.2 \%$. The observed reduction is lower than theoretically expected from the basic cycle modeled data presented in Table 2. This difference is likely due to the approximately $1 \mathrm{~K}$ higher average superheating degree of R450A system that affects the isentropic efficiency and isentropic compression work. A slight variation of compressor power consumption is a combined effect of the specific compression work degradation (Figure 7) that is compensated by the increase in the refrigerant mass flow through the observed range of the evaporation temperatures.

Figure 8 presents COP values obtained from the experimental measurements of both refrigerants R134a and R450A. Although power consumption during R450A compression is lower than during R134a compression, the noticeable reduction in cooling capacity of R450A results in lower COP, that is $2.9 \%$ lower (on average) over the entire range of tested conditions. Even though the previous experimental study of Mota-Babiloni et al. (2015a) indicates that $\mathrm{R} 450 \mathrm{~A}$ can have comparable COP to R134a, in the present study the R450A performance is likely influenced by slightly higher superheating and the non-optimized refrigeration system components.

Given that the aim of this work is to perform a drop-in replacement using R450A in the R134a small capacity refrigeration system, better performance would be expected if the system would be improved for the use of this new mixture. For instance, a specially designed compressor can improve the efficiency of the modified system. Besides, selection of larger compressor to match R134a cooling capacity could have a positive effect on COP.

\subsection{Discharge line temperature}


The compressor discharge temperatures measurements are presented in Figure 9. The observed values are $1 \mathrm{~K}$ lower for R450A than for R134a, which is in line with the expectations that follow from the theoretical calculation and previous experimental studies. Eventual deviations are mainly due to the varying superheat degree and effect of the different ambient temperatures during the tests.

\section{Conclusions}

The use of R134a should be significantly reduced in coming future. Due to the lack of information available about the R450A experimental behavior in different refrigeration systems, in this paper, we investigate the feasibility of R450A (HFC/HFO mixture with GWP value of 547) as a drop-in alternative to R134a in a small capacity refrigeration test bench.

From a thermophysical point of view, R450A is similar to R134a, even though the HFO $\mathrm{R} 1234 \mathrm{ze}(\mathrm{E})$ constitutes the greater part of the mixture (58\% compared to $42 \%$ ). The major differences were identified in relative molar mass, vapor density, and liquid thermal conductivity. Moreover, R450A is a zeotropic mixture and exhibits slight temperature glide.

Experimental data was obtained varying evaporating temperature at steps of $2.5^{\circ} \mathrm{C}$ between -15 and $12.5^{\circ} \mathrm{C}$ and condensing temperature at 25,30 and $35^{\circ} \mathrm{C}$. Results indicate that compression pressure ratio is almost unaffected when R450A is used instead of R134a in the analyzed system. The resulting compressor discharge temperatures are similar as well. However, noticeable variation is seen for the mass flow rate that is $9.1 \%$ lower for R450A on average. Observed cooling capacity measurements indicate a reduction of cooling capacity for R450A $(9.9 \%$ decrease). Electric power consumption is reduced as well so that the resulting COP values show $2.9 \%$ decrease for R450A as compared to R134a.

The results of this study suggest that R450A can be considered as a drop-in replacement to $\mathrm{R} 134 \mathrm{a}$ in small capacity refrigeration systems where a reduction in refrigerant GWP is necessary, and the decrease in cooling capacity is acceptable. However, a slight reduction in energy performance can be anticipated because of such replacement. These drawbacks can be potentially mitigated in newly designed systems where components are fully optimized for being used with R450A refrigerant.

\section{Acknowledgements}

This research is done within the Effsys Expand P08 project that is funded by the Swedish Energy Agency with the support of Danfoss Värmepumpar AB, Nibe AB, Nowab, Svensk Energi \& Kylanalys AB, Bosch Thermoteknik AB, and Svenska Kyltekniska Föreningen. A. 
Mota-Babiloni would like to acknowledge the funding received from the Plan for the promotion of research of the Universitat Jaume I for the year 2016 (POSDOC/2016/23).

\section{References}

AHRI, 2015. Participants' Handbook: AHRI Low GWP Alternative Refrigerants Evaluation Program (Low-GWP AREP).

Aprea, C., Greco, A., Maiorino, A., 2012. An experimental evaluation of the greenhouse effect in the substitution of R134a with CO2. Energy 45, 753-761.

Bolaji, B.O., 2010. Experimental study of R152a and R32 to replace R134a in a domestic refrigerator. Energy 35, 3793-3798.

European Commission, 2017. Proposal for a COUNCIL DECISION on the conclusion of the agreement to amend the Montreal Protocol on substances that deplete the ozone layer adopted in Kigali. Brussels, Belgium. https://ec.europa.eu/clima/sites/clima/files/fgas/docs/com_2017_51_en.pdf

GISTEMP Team, 2016. GISS Surface Temperature Analysis (GISTEMP). NASA Goddard Institute for Space Studies. https://data.giss.nasa.gov/gistemp/

Kontomaris, K., Kulankara, S., Kauffman, J.P., 2013. A reduced global warming potential replacement for HFC-134a in centrifugal chillers: XP10 measured performance and projected climate impact. HVAC\&R Res. 19, 857-864.

Lee, M.Y., Lee, D.Y., Kim, Y., 2008. Performance characteristics of a small-capacity directly cooled refrigerator using R290/R600a (55/45). Int. J. Refrig. 31, 734-741.

Lemmon, E.W., Huber, M.L., McLinden, M.O., 2013. NIST Standard Reference Database 23: Reference Fluid Thermodynamic and Transport Properties-REFPROP, Version 9.1. National Institute of Standards and Technology, Standard Reference Data Program, Gaithersburg, MD, USA.

McLinden, M.O., Kazakov, A.F., Brown, J.S., Domanski, P.A., 2014. A thermodynamic analysis of refrigerants: Possibilities and tradeoffs for Low-GWP refrigerants. Int. J. Refrig. 38, 80-92.

Mendoza-Miranda, J.M., Mota-Babiloni, A., Navarro-Esbrí, J., 2016a. Evaluation of R448A and R450A as low-GWP alternatives for R404A and R134a using a micro-fin tube evaporator model. Appl. Therm. Eng. 98, 330-339.

Mendoza-Miranda, J.M., Mota-Babiloni, A., Ramírez-Minguela, J.J., Muñoz-Carpio, V.D., Carrera-Rodríguez, M., Navarro-Esbrí, J., 2016b. Comparative evaluation of R1234yf, $\mathrm{R} 1234 \mathrm{ze}(\mathrm{E})$ and $\mathrm{R} 450 \mathrm{~A}$ as alternatives to R134a in a variable speed reciprocating compressor. Energy 114, 753-766. 
Moffat, R. J., 1988. Describing the uncertainties in experimental results. Exp. Thermal Fluid Sci. $1,3-17$.

Molés, F., Navarro-Esbrí, J., Peris, B., Mota-Babiloni, A., Barragán-Cervera, Á., 2014. Theoretical energy performance evaluation of different single stage vapour compression refrigeration configurations using R1234yf and R1234ze(E) as working fluids. Int. J. Refrig. 44, $141-150$.

Mota-Babiloni, A., Navarro-Esbrí, J., Barragán-Cervera, Á., Molés, F., Peris, B., 2015a. Experimental study of an R1234ze(E)/R134a mixture (R450A) as R134a replacement. Int. J. Refrig. 51, 52-58.

Mota-Babiloni, A., Navarro-Esbrí, J., Barragán-Cervera, Á., Molés, F., Peris, B., 2015b. Dropin analysis of an internal heat exchanger in a vapour compression system using R1234ze(E) and R450A as alternatives for R134a. Energy 90, 1636-1644.

Mota-Babiloni, A., Navarro-Esbrí, J., Molés, F., Barragán-Cervera, Á., Peris, B., Verdú, G., 2016. A review of refrigerant R1234ze(E) recent investigations. Appl. Therm. Eng. 95, 211-222.

Mota-Babiloni, A., Makhnatch, P., Khodabandeh, R., Navarro-Esbrí, J., 2017. Experimental assessment of R134a and its lower GWP alternative R513A. Int. J. Refrig. 74, 682-688.

Myhre, G., Shindell, D., Bréon, F.-M., Collins, W., Fuglestvedt, J., Huang, J., et al., 2013. Anthropogenic and natural radiative forcing. In: Climate Change 2013: The Physical Science Basis. Contribution of Working Group I to the Fifth Assessment Report of the Intergovernmental Panel on Climate Change. Cambridge University Press, Cambridge, United Kingdom and New York, NY, USA.

Ortega Sotomayor, P., Reis Parise, J.A., 2016. Characterization and simulation of an open piston compressor for application on automotive air-conditioning systems operating with R134a, R1234yf and R290. Int. J. Refrig. 61, 100-116.

Qi, Z., 2015. Performance improvement potentials of R1234yf mobile air conditioning system. Int. J. Refrig. 58, 35-40.

Raabe, G., 2016. Molecular simulation studies in hydrofluoroolefine (HFO) working fluids and their blends. Sci. Technol. Built Environ. 22, 1-13.

Rasti, M., Aghamiri, S.F., Hatamipour, M.S., 2013. Energy efficiency enhancement of a domestic refrigerator using R436A and R600a as alternative refrigerants to R134a. Int. J. Therm. Sci. 74, 86-94.

Schultz, K., Kujak, S., 2013. System drop-in tests of R134a alternative refrigerants (ARM-42a, N-13a, N-13b, R-1234ze(E), and Opteon XP10) in a 230-RT water-cooled Water chiller. AirConditioning, Heating, and Refrigeration Institute (AHRI) Low-GWP Alternative Refrigerants Evaluation Program (Low-GWP AREP). Test report \#7. 
United Nations, 2015. The Paris Agreement (English version). http://unfccc.int/files/essential_background/convention/application/pdf/english_paris_agreement .pdf

World Meteorological Organization, 2014. Scientific Assessment of Ozone Depletion: 2014. Geneva, Switzerland. 


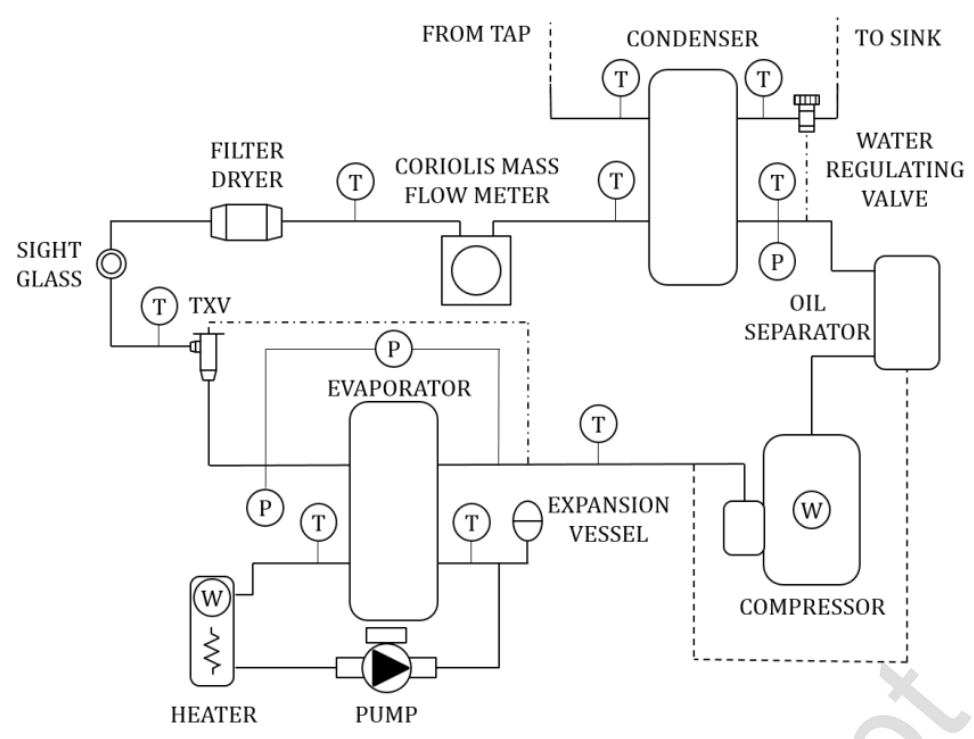

Figure 1. Schematic diagram of the experimental test bench

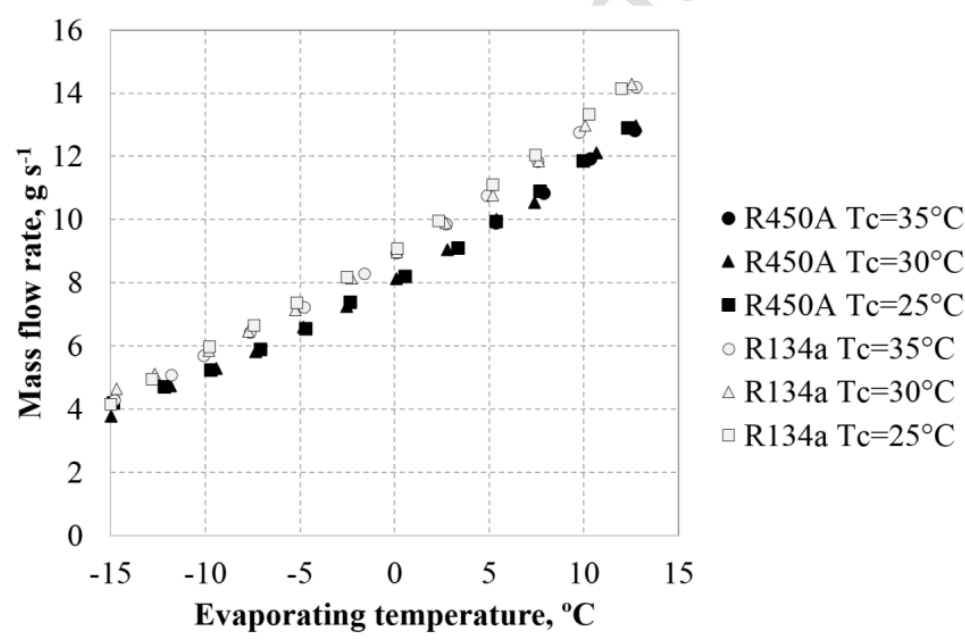

Figure 2. Experimental mass flow rate at different evaporating and condensing temperatures 


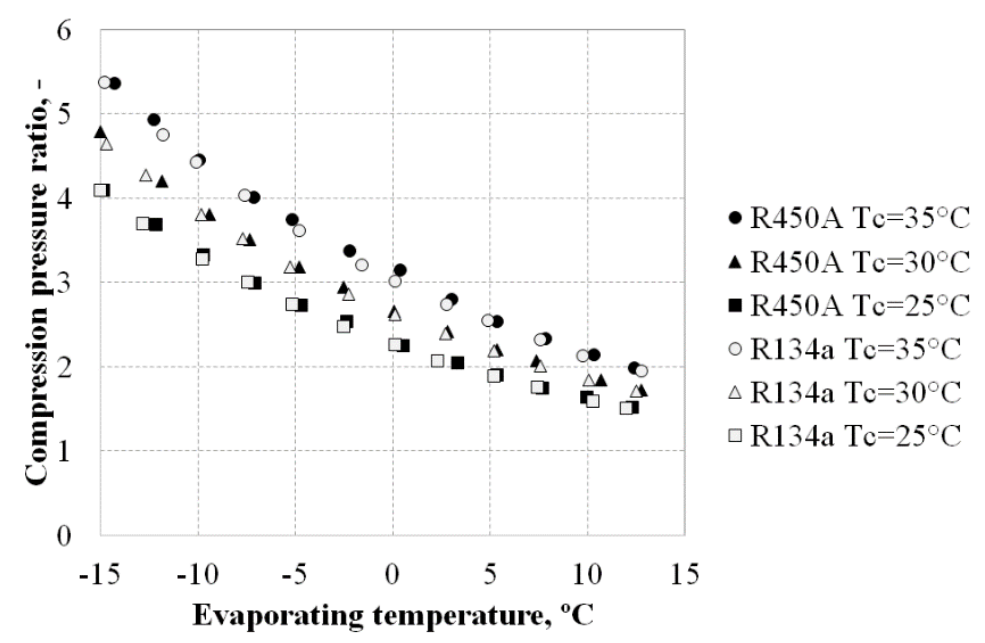

Figure 3. Compression pressure ratio

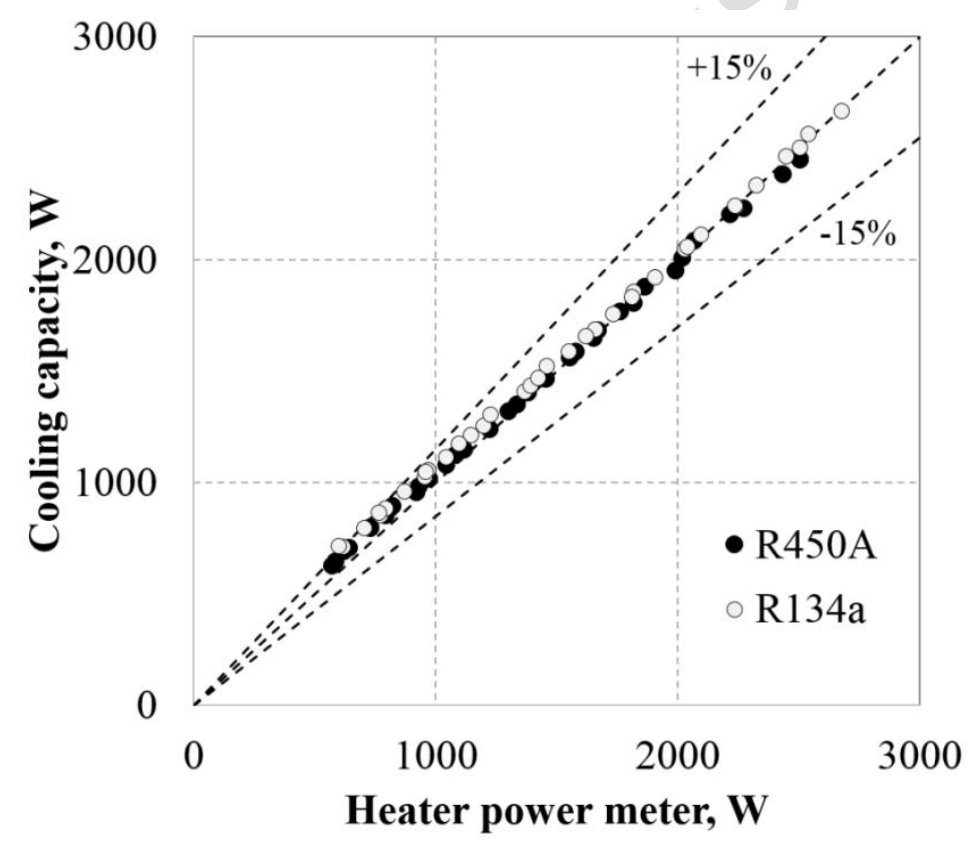

Figure 4. Evaporator heat balance 


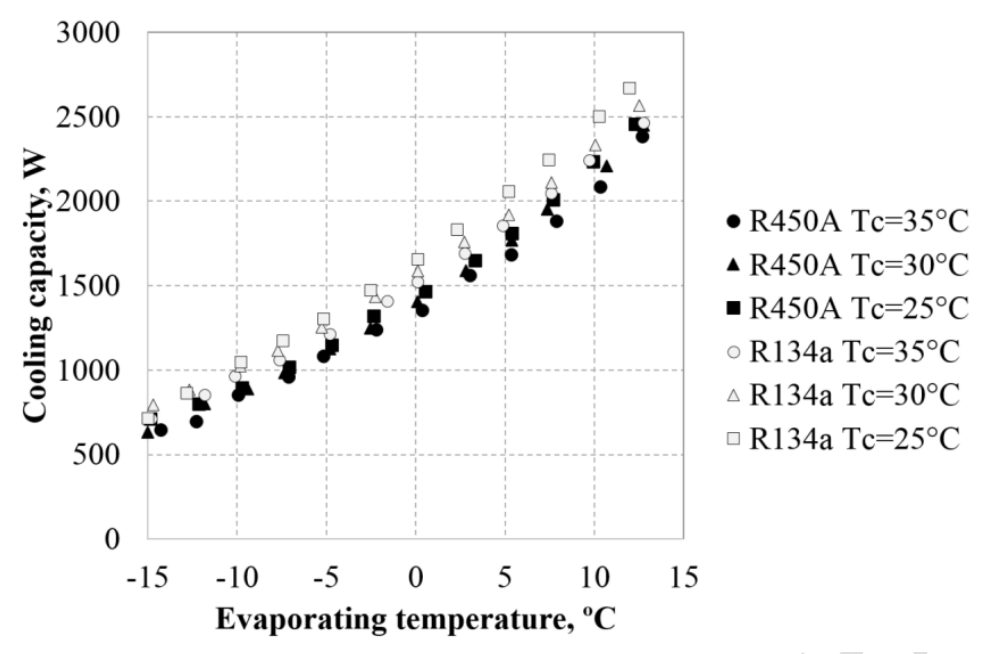

Figure 5. Cooling capacity at different evaporating and condensing temperatures

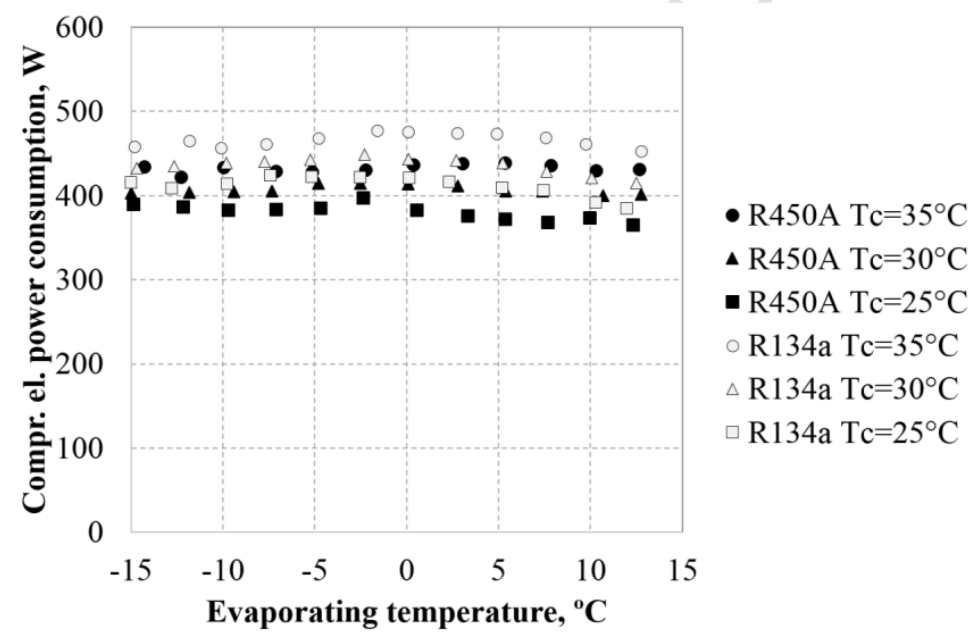

Figure 6. Power consumption at different evaporating and condensing temperatures

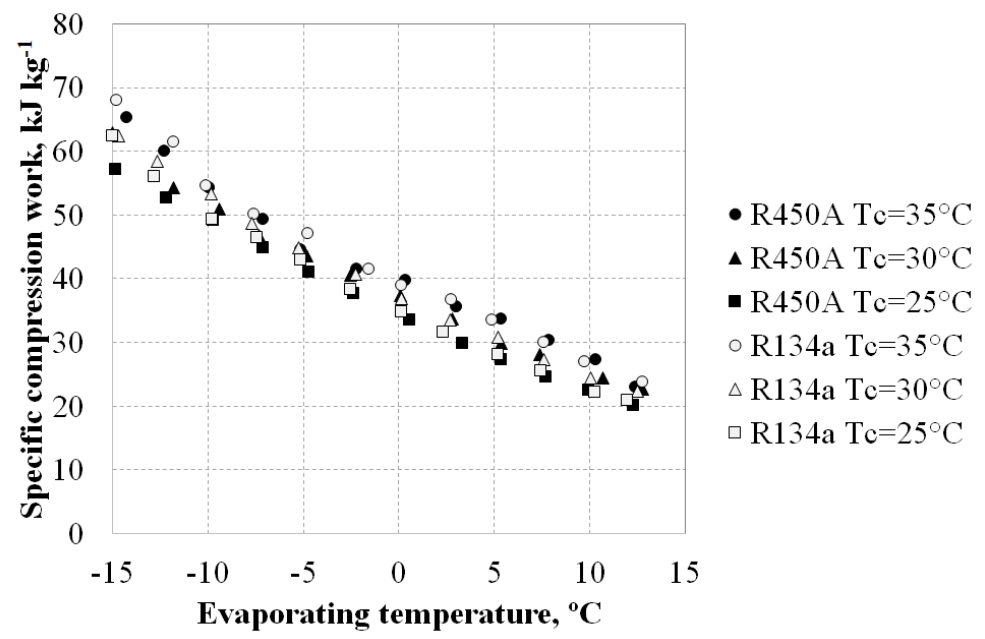

Figure 7. Specific compression work at different evaporating and condensing temperatures 


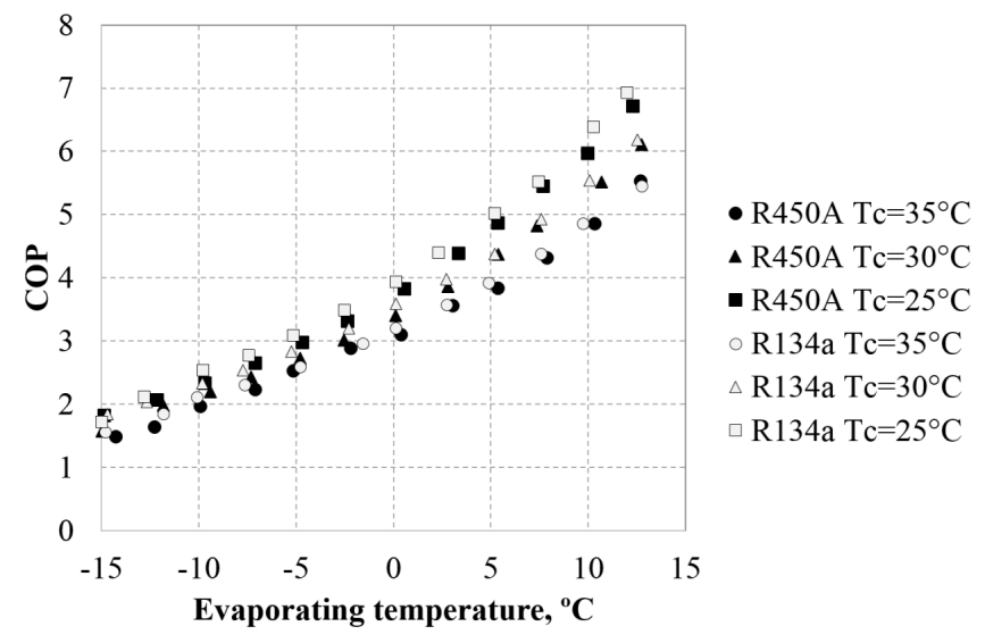

Figure 8. COP at different evaporating and condensing temperatures

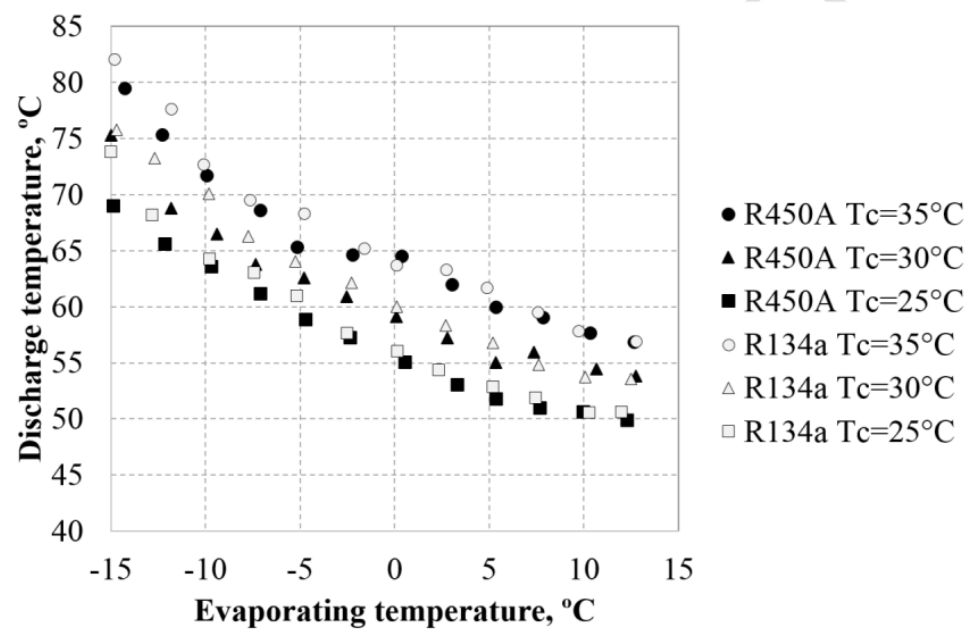

Figure 9. Discharge line temperatures at different evaporating and condensing temperatures 
Table 1. Main characteristics of R450A and R134a (Lemmon et al., 2013).

\begin{tabular}{|c|c|c|}
\hline & R450A & R134a \\
\hline Chemical notation & $\begin{array}{c}42 \% \text { R134a / } 58 \% \\
\text { R1234ze(E) }\end{array}$ & $100 \% \mathrm{R} 134 \mathrm{a}$ \\
\hline ANSI/ASHRAE Standard safety classification & A1 & A1 \\
\hline GWP (Myhre et al., 2013) & 547 & 1300 \\
\hline Relative molar mass, $\mathrm{g} \mathrm{mol}^{-1}$ & 108.69 & 102.03 \\
\hline Critical temperature, ${ }^{\circ} \mathrm{C}$ & 104.47 & 101.06 \\
\hline Critical pressure, $\mathrm{MPa}$ & 3.82 & 4.06 \\
\hline Normal boiling point, ${ }^{\circ} \mathrm{C}$ & -23.36 & -26.07 \\
\hline Glide at $0.1 \mathrm{MPa}, \mathrm{K}$ & 0.61 & 0.00 \\
\hline Liquid density $^{\mathrm{a}}, \mathrm{kg} \mathrm{m}^{-3}$ & 1259.64 & 1294.78 \\
\hline Vapor density $^{\mathrm{a}}, \mathrm{kg} \mathrm{m}^{-3}$ & 13.18 & 14.43 \\
\hline Liquid $c_{\mathrm{p}}{ }^{\mathrm{a}}, \mathrm{kJ} \mathrm{kg}^{-1} \mathrm{~K}^{-1}$ & 1.33 & 1.34 \\
\hline Vapor $\mathrm{c}_{\mathrm{p}}{ }^{\mathrm{a}}, \mathrm{kJ} \mathrm{kg}^{-1} \mathrm{~K}^{-1}$ & 0.89 & 0.90 \\
\hline Specific heat ratio $\mathrm{c}_{\mathrm{p}} / \mathrm{c}_{\mathrm{v}}{ }^{\mathrm{a}},-$ & 1.15 & 1.18 \\
\hline Liquid thermal conductivity ${ }^{\mathrm{a}}, \mathrm{mW} \mathrm{m}^{-1} \mathrm{~K}^{-1}$ & 86.23 & 92.01 \\
\hline Vapor thermal conductivity ${ }^{\mathrm{a}}, \mathrm{mW} \mathrm{m} \mathrm{m}^{-1} \mathrm{~K}^{-1}$ & 11.70 & 11.51 \\
\hline Liquid viscosity ${ }^{\mathrm{a}}, \mu \mathrm{Pa} \mathrm{s}$ & 264.23 & 266.53 \\
\hline Vapor viscosity $^{\mathrm{a}}, \mu \mathrm{Pa} \mathrm{s}$ & 11.16 & 10.73 \\
\hline
\end{tabular}

Table 2. Theoretical overview of R450A and R134a performance.

\begin{tabular}{|c|c|c|}
\hline$P>$ & R450A & R134a \\
\hline Evaporating pressure, $\mathrm{MPa}$ & 0.21 & 0.24 \\
\hline Condensing pressure, $\mathrm{MPa}$ & 0.68 & 0.77 \\
\hline Compressor discharge temperature, ${ }^{\circ} \mathrm{C}$ & 51.9 & 55.4 \\
\hline Refrigerating effect, $\mathrm{kJ} \mathrm{kg}^{-1}$ & 163.2 & 172.2 \\
\hline Specific compression work, $\mathrm{kJ} \mathrm{kg}^{-1}$ & 34.03 & 36.03 \\
\hline Vapor density at the compressor inlet, $\mathrm{kg} \mathrm{m}^{-3}$ & 10.54 & 11.48 \\
\hline Volumetric cooling capacity, $\mathrm{kJ} \mathrm{m}^{-3}$ & 1720 & 1977 \\
\hline $\mathrm{COP},-$ & 4.79 & 4.78 \\
\hline
\end{tabular}


Table 3. Tests operating conditions.

\begin{tabular}{lcc}
\hline Operating conditions & R450A & R134a \\
\hline Evaporating temperatures, ${ }^{\circ} \mathrm{C}$ & {$[-15,12.5]$ at steps of 2.5} \\
Condensing temperatures, ${ }^{\circ} \mathrm{C}$ & \multicolumn{2}{c}{25,30 and 35} \\
Average measured superheating degree, $\mathrm{K}$ & 12.1 & 10.9 \\
Average measured subcooling degree, $\mathrm{K}$ & 11.2 & 6.4 \\
Refrigerant amount, $\mathrm{kg}$ & 0.500 & 0.450 \\
\hline
\end{tabular}

Table 4. Summary of R134a tests

\begin{tabular}{|c|c|c|c|c|c|c|c|c|c|}
\hline$T_{\text {evap }}$ & $T_{\mathrm{c}}$ & $S H D$ & $S C D$ & $T_{\text {disc }}$ & $T_{\mathrm{amb}}$ & $\dot{m}_{r e f}$ & $\dot{Q}_{\text {evap }}$ & $P_{\text {comp }}$ & COP \\
\hline${ }^{\circ} \mathrm{C}$ & ${ }^{\circ} \mathrm{C}$ & $\mathrm{K}$ & $\mathrm{K}$ & ${ }^{\circ} \mathrm{C}$ & ${ }^{\circ} \mathrm{C}$ & $\mathrm{g} \mathrm{s}^{-1}$ & $\mathrm{~W}$ & $\mathrm{~W}$ & - \\
\hline 12.78 & 34.93 & 11.21 & 3.36 & 56.90 & 26.93 & 14.19 & 2464.6 & 452.5 & 5.45 \\
\hline 9.75 & 34.52 & 11.04 & 3.45 & 57.85 & 27.00 & 12.75 & 2240.0 & 461.0 & 4.86 \\
\hline 7.60 & 35.02 & 10.83 & 4.90 & 59.49 & 27.18 & 11.83 & 2046.2 & 468.1 & 4.37 \\
\hline 4.90 & 35.08 & 11.21 & 5.10 & 61.65 & 26.91 & 10.75 & 1854.1 & 473.2 & 3.92 \\
\hline 2.75 & 34.99 & 10.98 & 6.27 & 63.28 & 27.12 & 9.85 & 1688.8 & 473.5 & 3.57 \\
\hline 0.11 & 35.00 & 10.84 & 6.97 & 63.70 & 27.07 & 8.94 & 1521.2 & 475.1 & 3.20 \\
\hline-1.58 & 35.04 & 10.81 & 7.40 & 65.20 & 25.27 & 8.28 & 1408.0 & 476.6 & 2.95 \\
\hline-4.78 & 35.00 & 10.49 & 7.37 & 68.26 & 27.44 & 7.22 & 1210.7 & 467.8 & 2.59 \\
\hline-7.62 & 35.04 & 10.44 & 6.75 & 69.48 & 27.17 & 6.41 & 1056.9 & 460.4 & 2.30 \\
\hline-10.09 & 34.92 & 10.80 & 10.67 & 72.66 & 26.82 & 5.68 & 961.2 & 456.4 & 2.11 \\
\hline-11.80 & 35.04 & 9.94 & 11.37 & 77.63 & 26.42 & 5.08 & 853.1 & 464.7 & 1.84 \\
\hline-14.79 & 35.08 & 9.82 & 11.71 & 82.03 & 26.23 & 4.28 & 711.9 & 457.7 & 1.56 \\
\hline 12.52 & 30.03 & 11.47 & 2.83 & 53.59 & 25.33 & 14.29 & 2564.3 & 414.9 & 6.18 \\
\hline 10.08 & 29.94 & 11.12 & 3.35 & 53.73 & 25.29 & 12.99 & 2332.9 & 421.2 & 5.54 \\
\hline 7.61 & 30.05 & 10.71 & 4.39 & 54.83 & 25.19 & 11.86 & 2111.0 & 428.9 & 4.92 \\
\hline 5.21 & 30.05 & 10.64 & 5.15 & 56.79 & 26.14 & 10.77 & 1920.4 & 438.9 & 4.38 \\
\hline 2.71 & 30.04 & 11.07 & 6.00 & 58.35 & 26.16 & 9.89 & 1757.0 & 441.8 & 3.98 \\
\hline 0.11 & 30.09 & 11.01 & 6.68 & 59.98 & 26.31 & 8.98 & 1586.7 & 442.8 & 3.58 \\
\hline-2.28 & 30.03 & 10.79 & 7.48 & 62.14 & 26.28 & 8.13 & 1433.6 & 448.6 & 3.20 \\
\hline-5.25 & 29.92 & 10.52 & 8.63 & 64.02 & 26.42 & 7.14 & 1254.2 & 442.3 & 2.84 \\
\hline-7.72 & 30.04 & 10.49 & 7.70 & 66.28 & 26.42 & 6.45 & 1114.3 & 439.7 & 2.53 \\
\hline-9.81 & 29.99 & 11.16 & 9.94 & 70.09 & 27.20 & 5.86 & 1023.9 & 438.5 & 2.33 \\
\hline-12.67 & 29.99 & 10.92 & 9.71 & 73.22 & 27.33 & 5.11 & 882.1 & 434.7 & 2.03 \\
\hline-14.69 & 30.04 & 10.83 & 9.93 & 75.76 & 27.36 & 4.65 & 795.8 & 432.8 & 1.84 \\
\hline 11.99 & 25.04 & 12.16 & 3.93 & 50.62 & 26.06 & 14.15 & 2667.7 & 384.9 & 6.93 \\
\hline 10.28 & 24.99 & 11.90 & 4.28 & 50.57 & 26.21 & 13.32 & 2500.3 & 391.6 & 6.38 \\
\hline 7.45 & 25.11 & 11.54 & 5.28 & 51.87 & 26.06 & 12.04 & 2243.5 & 406.6 & 5.52 \\
\hline 5.20 & 25.09 & 11.37 & 5.72 & 52.87 & 26.00 & 11.09 & 2057.2 & 409.7 & 5.02 \\
\hline 2.32 & 24.71 & 11.17 & 5.62 & 54.35 & 25.98 & 9.96 & 1831.2 & 416.2 & 4.40 \\
\hline
\end{tabular}




\begin{tabular}{llllllllll}
0.13 & 25.02 & 10.87 & 5.75 & 56.04 & 25.91 & 9.08 & 1655.0 & 420.7 & 3.93 \\
-2.52 & 24.83 & 10.70 & 5.04 & 57.63 & 25.81 & 8.18 & 1470.0 & 422.0 & 3.48 \\
-5.16 & 24.88 & 10.97 & 4.53 & 60.99 & 28.08 & 7.35 & 1302.7 & 422.2 & 3.09 \\
-7.42 & 25.00 & 10.89 & 5.55 & 63.06 & 27.84 & 6.63 & 1173.6 & 424.0 & 2.77 \\
-9.78 & 24.98 & 10.71 & 5.80 & 64.28 & 27.54 & 5.96 & 1047.0 & 413.6 & 2.53 \\
-12.81 & 24.91 & 9.80 & 6.88 & 68.19 & 27.00 & 4.95 & 862.8 & 408.5 & 2.11 \\
-15.03 & 25.08 & 10.35 & 6.40 & 73.78 & 26.82 & 4.14 & 714.5 & 415.5 & 1.72 \\
\hline
\end{tabular}


Table 5. Summary of R450A tests

\begin{tabular}{|c|c|c|c|c|c|c|c|c|c|}
\hline$T_{\text {evap }}$ & $T_{\mathrm{c}}$ & $S H D$ & $S C D$ & $T_{\mathrm{disc}}$ & $T_{\mathrm{amb}}$ & $\dot{m}_{r e f}$ & $\dot{Q}_{\text {evap }}$ & $P_{\text {comp }}$ & $C O P$ \\
\hline${ }^{\circ} \mathrm{C}$ & ${ }^{\circ} \mathrm{C}$ & K & $\mathrm{K}$ & ${ }^{\circ} \mathrm{C}$ & ${ }^{\circ} \mathrm{C}$ & $\mathrm{g} \mathrm{s}^{-1}$ & $\mathrm{~W}$ & $\mathrm{~W}$ & - \\
\hline 12.39 & 34.42 & 12.52 & 12.29 & 55.87 & 23.70 & 12.60 & 2285.9 & 412.5 & 5.54 \\
\hline 10.32 & 34.70 & 11.21 & 10.09 & 57.68 & 25.25 & 11.93 & 2086.6 & 429.8 & 4.85 \\
\hline 7.86 & 34.70 & 11.22 & 9.96 & 59.08 & 25.25 & 10.85 & 1882.0 & 435.7 & 4.32 \\
\hline 5.35 & 34.69 & 10.49 & 10.68 & 59.98 & 26.54 & 9.90 & 1685.1 & 438.6 & 3.84 \\
\hline 3.03 & 34.83 & 12.20 & 13.53 & 61.97 & 23.91 & 8.97 & 1560.7 & 438.0 & 3.56 \\
\hline 0.37 & 34.70 & 12.52 & 13.64 & 64.51 & 23.89 & 7.84 & 1353.8 & 436.8 & 3.10 \\
\hline-2.23 & 34.74 & 12.68 & 11.81 & 64.61 & 23.62 & 7.30 & 1241.6 & 430.6 & 2.88 \\
\hline-5.16 & 34.91 & 12.35 & 12.48 & 65.35 & 23.69 & 6.48 & 1082.2 & 428.0 & 2.53 \\
\hline-7.11 & 34.74 & 12.32 & 12.13 & 68.60 & 21.85 & 5.82 & 959.5 & 428.9 & 2.24 \\
\hline-9.95 & 34.72 & 12.42 & 12.10 & 71.69 & 21.77 & 5.23 & 852.8 & 433.2 & 1.97 \\
\hline-12.28 & 34.65 & 12.10 & 12.05 & 75.34 & 21.66 & 4.31 & 695.3 & 422.4 & 1.65 \\
\hline-14.28 & 34.75 & 12.46 & 15.06 & 79.50 & 21.70 & 3.96 & 647.7 & 434.0 & 1.49 \\
\hline 12.76 & 29.79 & 12.15 & 15.66 & 53.84 & 22.51 & 12.97 & 2450.5 & 401.4 & 6.10 \\
\hline 10.68 & 29.65 & 12.46 & 10.94 & 54.44 & 25.73 & 12.11 & 2206.5 & 399.8 & 5.52 \\
\hline 7.38 & 29.87 & 12.45 & 15.50 & 55.96 & 22.50 & 10.55 & 1953.7 & 405.5 & 4.82 \\
\hline 5.37 & 29.61 & 10.98 & 10.80 & 55.02 & 25.52 & 10.01 & 1770.0 & 404.9 & 4.37 \\
\hline 2.80 & 29.74 & 11.11 & 10.89 & 57.22 & 25.64 & 9.05 & 1589.1 & 411.3 & 3.86 \\
\hline 0.10 & 29.67 & 11.25 & 10.47 & 59.14 & 24.70 & 8.12 & 1405.2 & 413.6 & 3.40 \\
\hline-2.53 & 29.79 & 11.61 & 10.52 & 60.92 & 24.65 & 7.24 & 1247.3 & 414.2 & 3.01 \\
\hline-4.80 & 29.66 & 11.80 & 10.54 & 62.54 & 24.59 & 6.59 & 1126.6 & 414.2 & 2.72 \\
\hline-7.33 & 29.63 & 11.51 & 10.85 & 63.75 & 24.63 & 5.82 & 983.5 & 405.3 & 2.43 \\
\hline-9.41 & 29.59 & 11.64 & 10.95 & 66.50 & 24.59 & 5.29 & 886.6 & 404.1 & 2.19 \\
\hline-11.83 & 29.69 & 12.38 & 13.00 & 68.80 & 23.46 & 4.73 & 799.3 & 403.9 & 1.98 \\
\hline-14.99 & 29.73 & 12.50 & 13.17 & 75.26 & 21.64 & 3.77 & 630.1 & 402.6 & 1.57 \\
\hline 12.30 & 25.02 & 12.65 & 11.86 & 49.90 & 22.59 & 12.90 & 2455.2 & 365.3 & 6.72 \\
\hline 9.95 & 24.89 & 12.63 & 11.48 & 50.67 & 22.45 & 11.86 & 2233.9 & 373.9 & 5.98 \\
\hline 7.68 & 24.53 & 12.41 & 9.38 & 50.98 & 24.54 & 10.90 & 2008.5 & 368.1 & 5.46 \\
\hline 5.36 & 24.63 & 12.07 & 9.01 & 51.79 & 24.66 & 9.95 & 1809.1 & 371.9 & 4.86 \\
\hline 3.32 & 24.75 & 12.13 & 9.56 & 53.06 & 23.95 & 9.11 & 1649.9 & 376.3 & 4.39 \\
\hline 0.55 & 24.63 & 12.39 & 8.94 & 55.08 & 24.44 & 8.20 & 1466.0 & 382.7 & 3.83 \\
\hline-2.36 & 24.91 & 12.23 & 10.68 & 57.30 & 22.18 & 7.39 & 1319.7 & 397.8 & 3.32 \\
\hline-4.71 & 24.50 & 12.33 & 8.93 & 58.91 & 24.09 & 6.56 & 1148.8 & 385.2 & 2.98 \\
\hline-7.11 & 24.54 & 12.37 & 8.25 & 61.20 & 24.26 & 5.91 & 1019.1 & 383.6 & 2.66 \\
\hline-9.71 & 24.60 & 12.24 & 8.45 & 63.59 & 24.27 & 5.25 & 896.0 & 383.2 & 2.34 \\
\hline-12.17 & 24.74 & 12.40 & 8.62 & 65.62 & 23.13 & 4.72 & 798.5 & 386.4 & 2.07 \\
\hline-14.87 & 24.56 & 13.36 & 9.36 & 69.00 & 23.19 & 4.20 & 710.7 & 390.0 & 1.82 \\
\hline
\end{tabular}


Table 6. Maximum and minimum experimental velocities at the test bench lines

\begin{tabular}{lccccc}
\hline Velocity $\left(\mathbf{m ~ s}^{-1}\right)$ at & Inner diameter $(\mathbf{m m})$ & \multicolumn{2}{c}{ R134a } & \multicolumn{2}{c}{ R450A } \\
\hline Suction line & 7.74 & 11.31 & 14.97 & 11.30 & 14.97 \\
Discharge line & 10.22 & 1.53 & 6.10 & 1.50 & 5.90 \\
Liquid line & 10.22 & 0.04 & 0.15 & 0.04 & 0.13 \\
\hline
\end{tabular}

